managers in WWF's regional teams - to ensure that accountability on the use of funds is provided regularly by WWF to its donor public.

While the bulk of WWF money may still be raised through appeals to the public's generosity in the form of subscriptions, donations, and legacies, additional support will be sought from commerce and industry, from bilateral and multilateral aid agencies, and through licensing WWF's Panda symbol. Every cent or penny that is donated to WWF International for conservation will continue to be used for that purpose, fund-raising and basic administration costs being already covered by income from capital funds such as the 1001 Club, A Nature Trust, and various commercial activities.

\section{Communications}

Under WWF's new strategy, communication of information will be a major support-tool in all phases of accomplishing its mission, including building environmental awareness and increasing understanding of WWF activities. One of the major areas of growth at the international headquarters, this Division will step up its experti- se in advertising and public relations, establish a broadcasting unit, and position itself as a media centre servicing the WWF family on a rapid-fire and accurate basis.

This unit will increase public awareness at all levels of society, ranging from the village centre (where, for instance, tribal and local people glean information) to major cities of the world (where key decisions are made by government leaders). Through various media and personal contacts, WWF will transmit its message to decisionmakers, major organizations, and the general public.

WWF's revised mission and new strategy, which are the result of a year of intensive consultation within the world-wide WWF family and with outsiders, now guide the organization and its growing number of regular supporters - almost 4 millions - around the globe on a critically important course. The mission must succeed.

ElZABETH KeMF, Editor
WWF News
World Conservation Centre
Avenue du Mont-Blanc
1196 Gland, Switzerland.

\title{
The Swiss National Climate Programme (ProClim): Objectives and Prospects
}

\section{Introduction}

ProClim (Programme Climatologique), the Swiss National Climate Programme, was set up in 1987 on the initiative of the Swiss Academy of Sciences, following the recognition that Switzerland should participate in global efforts in climate research as a result of world-wide preoccupation with climate change. Indeed, as a highlydeveloped country, Switzerland contributes its share, albeit small, to 'greenhouse' gas concentrations in the atmosphere, and therefore has a responsibility to provide scientific and policy responses to the problem of global warming.

The objectives of the Swiss National Climate Programme are multidisciplinary of necessity, as may be seen from this overview of its scientific objectives. Furthermore, recognizing the fact that information is often poorly broadcast to the general public, a major effort is being made to transfer research results in a comprehensible manner to the press and general public. Clear public information is essential if one is to raise the awareness of the nonscientific community, the press, and politicians, to the acute consequences of global climate change and the urgent steps which need to be taken forthwith to limit global warming and concomitant changes. ProClim publishes an information brochure (ProClim News) on a regular basis, and has edited a book for the general public on the subject of global change (Schotterer \& Andermatt, Climate-Our Future?, Bern, 1990).

Advanced education, through short courses on very specific climate topics, is a further aim of the Swiss National Climate Programme, and yet another is the organization of workshops and conferences. Regular events of this nature in Switzerland would allow our small country to play an important role in the international climate community, which has come to occupy a particularly prominent position of late with active renewal of the debate on global climatic change.

\section{Fourfold Scientific Objectives of ProClim}

1. Process Understanding:- If we are to gain insight into the possible future trends of global change, it is essential to understand the mechanisms of the climate system itself. Of special interest to Switzerland are the links between small- or regional-scale atmospheric processes and global climate. For example, mountain barriers such as the Alps have a significant dynamic effect on the general circulation of the atmosphere, but are poorly represented in General Circulation Models (GCMs). The study of the dynamic effects of mountains, land-surface processes, cloud-radiation interactions, and the Earth's radiation budget, either through observation or through detailed numerical model studies, will ultimately lead to an improved understanding of climatically relevant small-scale processes. As a consequence, these processes could then be more adequately represented in GCMs, leading to improved predictability of climate and its evolution.

Detailed model studies can also be envisaged to investigate the impacts of climate change on The Biosphere (such as ecological sensitivity of the Alpine world) and the included hydrosphere (such as hydrological balance for water-supply and energy resources) and cryosphere (such as glacier and snowline advance or retreat). The various interactions and feedbacks between the general free atmosphere and what may be called the 'central biosphere', including The Biosphere's component hydrosphere and cryosphere, are summarized in Fig. 1.

2. Past Climate Reconstruction:- The use of so-called climate archives as an indicator of climates of the past and their natural fluctuations, is one area where Swiss science has excelled. Climatic indicators can be found in many types of records, such as glacial cores, marine and lake sediments, coral reefs, tree rings, and dust deposits in caves. The analysis of stratified sediments, gas content 


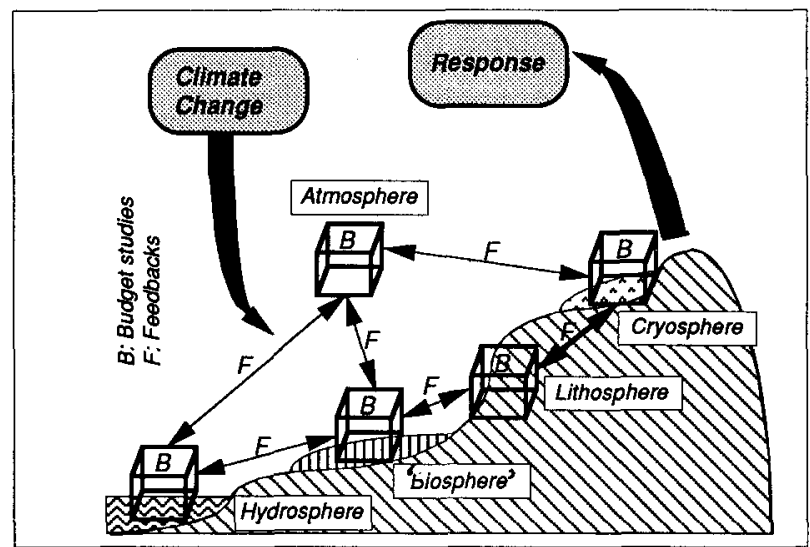

FIG. 1. Interactive processes between the general, free atmosphere and other Earth systems. For 'biosphere' (sic) read 'central biosphere (undefined)'.

of air bubbles trapped in ice, or the radioactivity of ancient organic material, has led to major insights into the instabilities inherent in the climate system and also into the transient fluctuations which characterized temperature and moisture trends of the past. Further information on more recent climates can be deduced from historical texts; indeed, a computerized data-bank is being set up in Bern on the basis of written records. The understanding of the behaviour of past climates allows us to equate the magnitude of natural climate variability and to quantify, for coming decades, to what extent anthropogenic activity can enhance climatic fluctuations. Furthermore, climatic archives provide a means to test GCM capability in simulating and analysing colder or warmer climates of the past.

3. Alpine Transect Study:- A study of the local climates of different regions within and on either side of the Alpine chain, is being envisaged in the framework of the Swiss National Climate Programme. Due to considerable differences in altitude, the Alpine world reproduces to a large extent the latitudinal climatic differences observed in the Northern Hemisphere. The Alpine Transect experiment plans to bring together specialists from a large number of backgrounds to look into present-day and past regional climates, climatic fluctuations and extremes, the cryosphere of high-Alpine regions, the hydrological balance of Swiss regions, ecological sensitivity to past and present climates, and the socio-economic problems which these regions may face as a result of abrupt climate change. Fig. 2 illustrates a possible network of test areas in Switzerland, each characteristic of a particular climatic regime. The multidisciplinary nature of this study will be possibly unique, and should allow a more global understanding than hitherto of the multiple facets of climate and climate change. Furthermore, analogies may be found between altitudinal variations of fauna and flora and latitudinal variations in vegetation and wildlife in both 'equilibrium' and transient climatic situations.

4. Socio-economic Aspects of Climate Change:While the physical magnitude of climate change is drawing much attention in the scientific community, it is clear that the societal impacts of global warming could be so extreme that they should be addressed now in order to prepare for the sometimes profound changes which are being variously projected. In a country such as Switzerland, global change would undoubtedly affect

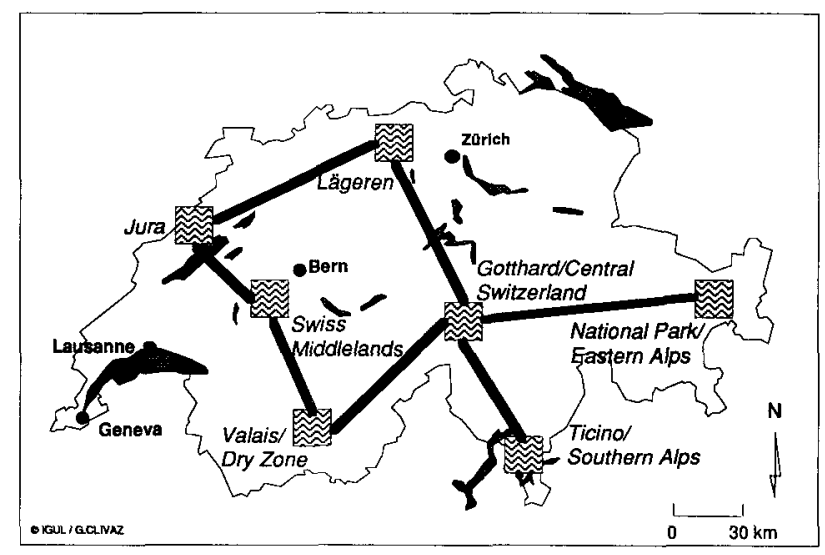

FIG. 2. Possible network of test-sites for the Alpine Transect experiments.

agriculture, tourism, and energy supply, through hydrological imbalances resulting from any serious temperaturerise. While a highly developed society such as Switzerland's may be able to cope with such problems, much of the less-developed world would be facing economic and social catastrophe; in this context, Swiss efforts should be focused on affordable technological transfers to developing countries. Such new technologies, adapted to local conditions, could help mitigate certain effects of global warming in the less-developed world.

The socio-economic aspect of ProClim activities is thus concerned not only with society's response to climate change within Switzerland, but also with the necessity of cooperation with the less-developed world. The Swiss National Climate Programme has, for the moment, chosen to seek to attain its research objectives through an interactive network of scientists, rather than through establishing a centralized research institute. Workshops on topics related to the above-mentioned fields are organized at regular intervals, and attempt to be openly interdisciplinary in nature. Experience has shown that this approach has been successful in allowing scientists from different backgrounds to meet, discuss, and plan future collaborative research.

\section{Conclusion}

ProClim has an ambitious research programme which it can fulfil only if certain conditions are met. A major prerequisite is to find the qualified personnel who will be capable of successfully achieving scientific aims. This is a crucial problem in a country whose total population is smaller than that of some of the larger European cities such as Paris or London. Scientists need to be motivated to remain in Switzerland to work on climate research, rather than to expatriate themselves to the larger research teams in some other parts of Europe or in North America. This could be achieved by offering medium- to long-term positions within institutes which can claim to have a potential for undertaking climate-related research.

ProClim also suffers from its new status within a longestablished structure in Switzerland. While ProClim is generally recognized by foreign groups to be the focus for climate research and coordination in Switzerland, this is perhaps not so well perceived in administrative circles within Switzerland, for various institutional reasons. This 
situation can lead to what might be considered as 'unhealthy competition' for funding and duplication of efforts, which can only be damaging to the long-term interests of climate research as a whole. It is hoped that this situation will improve in time, in order to allow ProClim to play fully its role of stimulation, coordination, and dissemination of the results, of climate research in Switzerland.
For further information on ProClim, readers should contact the undersigned:

\author{
Martin Beniston, Programme Director \\ ProClim-The Swiss National Climate Programme \\ Hirschengraben 11, PO Box 7613 \\ CH-3001 Bern, Switzerland. \\ Tel. +41-(0)312121 14 \\ Fax +41-(0)31229164
}

\section{Assessing Insect Species-richness at a Single Site}

\section{Introduction}

A recurrent problem that is apt to be encountered by anyone trying to decide whether a site is rich in species, is how much time and what type and degree of sampling are needed before a valid assessment can be made. The problem is particularly acute with insects, as it is usually difficult to know if sampling over a period of just one or two years can provide an accurate picture of the number of species present or apt to invade the site. There is an intuitive feeling that long-term sampling is necessary, especially as so many species are known to fluctuate in abundance from year to year. Thus it might be that at the beginning of a sampling programme a 'bad' year is chosen by chance, or perhaps an exceptionally 'good' year: either could give a false impression of the richness of a site.

Results of monitoring insect diversity and abundance in a garden at Leicester, England, UK, demonstrate that short-term sampling can provide information about the species-richness of a site which could be used in decisions about conservation.* However, this conclusion was possible only after a period of long-term monitoring during which the rate of accumulation of additional species was determined.

\section{The Site and its Diversity of Insect Fauna}

A description of the garden is given in Owen (1983). In summer it has been regularly monitored for insects since 1972, and the results of this monitoring have appeared in some 54 publications, one of the earliest of which suggested that gardens might well constitute England's most important Nature reserve (Owen \& Owen, 1975). In addition there exists a complete catalogue of all species of flowering plants (wild and cultivated), records of yearto-year changes in vegetation, lists of all vertebrates, annelids, and molluscs, and lists of selected groups of non-insect arthropods (spiders, harvestmen, isopods, and myriapods). The site must indeed be quite one of the best-catalogued in Britain. A detailed analysis of its fauna and flora, including a list of publications, will appear in a forthcoming book (J. Owen, in press).

The site's overall species-richness can be assessed by calculating the proportion of the known British insect fauna which is represented in those groups that have been well-studied: grasshoppers and crickets (Orthoptera), earwigs (Dermaptera), lacewings and their relatives (Neuroptera), butterflies and macro-moths (Lepidoptera), hoverflies (Diptera: Syrphidae), sawflies (Hymenoptera: Symphyta), ichneumons (Hymenoptera: Ichneumonidae), ants (Hymenoptera: Formicoidea), wasps (Hymenoptera: five superfamilies), bees (Hymenoptera: Apoidea), ground-beetles (Coleoptera:

* A referee comments that "insects are particularly good for estimating species diversity because they belong to several levels in the food-web and therefore could bring more [varied data] than other, rather restricted groups of animals.' - Ed.
Caraebidae), and ladybirds (Coleoptera: Coccinellidae). Each of those groups has been intensively sampled and monitored for 3-18 years, depending on the group, and it is thought that most (i.e. more than $80 \%$ ) of the species which are likely to occur have been recorded.

The combined total species in these groups recorded as occurring in the garden is 1,143 out of a possible 4,764 known from the British Isles, which is $24 \%$; but of course many of the British species are geographically or ecologically restricted and so would not be expected in the vicinity of Leicester. There is no comprehensive list of species in these groups for the Leicester area and, moreover, a remarkable number of the species recorded in the garden had hitherto remained unrecorded in the region. It is thus not possible to make a more local comparison.

There are estimated to be 22,500 species of insects in the British Isles and using the figure of $24 \%$ it can be predicted that about 5,400 species would be likely to be recorded in the garden if all groups were to be intensively sampled. This, however, is a minimum figure because even in the well-studied groups there are undoubtedly more species still to be found, especially in such families as the Ichneumonidae in which 533 of the 2,028 British species were recorded in only three years of sampling (Owen et al., 1981). Taking all insect groups together (i.e. the well-studied and the less well-studied), 1,671 species had been recorded by the end of 1989 , which is $30.9 \%$ of the predicted 5,400 present.

\section{Monitoring the Hoverflies (Syrphidae)}

In 18 consecutive years a Malaise trap, ${ }^{*}$ positioned in exactly the same place for the same period of each year (1

TABLE I

Numbers of Individuals (N) and of Species (S) of Syrphidae caught in a Malaise Trap in 18 Consecutive Years in a Suburban Garden in Leicester, England.

\begin{tabular}{lrrr}
\hline & $N$ & $S$ & species added \\
\hline 1972 & 1,339 & 47 & \\
1973 & 3,164 & 62 & 23 \\
1974 & 2,505 & 53 & 2 \\
1975 & 6,363 & 54 & 3 \\
1976 & 3,411 & 53 & 3 \\
1977 & 2,586 & 37 & 1 \\
1978 & 6,068 & 50 & 2 \\
1979 & 3,488 & 51 & 2 \\
1980 & 1,327 & 53 & 4 \\
1981 & 885 & 44 & 1 \\
1982 & 4,256 & 52 & 1 \\
1983 & 1,283 & 47 & - \\
1984 & 2,064 & 48 & 1 \\
1985 & 3,553 & 51 & 1 \\
1986 & 1,457 & 43 & 1 \\
1987 & 2,867 & 41 & \\
& & &
\end{tabular}

* Well figured in the only illustration in Owen \& Owen (1975). - Ed. 